\title{
REFERENCE VALUES FOR RESIDUAL VOLUME, FUNCTIONAL RESIDUAL CAPACITY AND TOTAL LUNG CAPACITY
}

\author{
ATS WORKSHOP ON LUNG VOLUME MEASUREMENTS \\ OFFICIAL STATEMENT OF THE EUROPEAN RESPIRATORY SOCIETY
}

\author{
J. Stocks*, Ph.H. Quanjer**
}

\section{CONTENTS}

1. Usefulness of reference values

2. Purpose of review

2.1 General considerations

2.2 Background

3. Published reference values

3.1 Reference values in infants

3.2 Reference values in preschool children

3.3 Reference values in children and adolescents

3.4 Reference values in adults

4. Recommendations
4.1 Selecting reference values

4.1.1 Selection of appropriate published reference data

4.1.2 Establishing specific reference values within a laboratory

4.1.3 Combination of data from several laboratories

4.2 Expression of results

4.3 Measuring ancillary variables

4.4 Future studies

5. Controversies

References

\section{Usefulness of reference values}

Reference values play an important role in establishing whether, in an individual, measured volumes fall within a range to be expected for a healthy person of the same sex, similar stature, age, and other characteristics. Hence, reference values should be chosen that are appropriate to the person being investigated. Ideally, the reference values should be consistent; in the context of this paper, it implies that predictions for the various lung volumes have been derived from the same reference population, with the same techniques. Comparing measured with reference values is fraught with difficulties, as it may lead to disease going undetected. This is because the scatter in predicted values is sufficiently large to allow a sick person to lose, e.g. much of his total lung capacity (TLC), whilst still remaining in the range observed in comparable healthy persons. In addition, measurements in an "abnormal range" are not diagnostic of a specific disease, as many diagnostic entities may cause

*Institute of Child Health, London, UK. **Physiology Department, Leiden University, Leiden, The Netherlands. Correspondence: J. Stocks, Portex Anaesthesia, Intensive Therapy and Respiratory Medicine Unit, Institute of Child Health, 30 Guilford Street, London WC1N $1 \mathrm{EH}, \mathrm{UK}$.

Keywords: Adolescent, adult, child, infant, lung volume, reference values. static lung volumes to be abnormal. Hence, in the follow-up of a patient, reliance should be placed much more on the effects of drugs or challenges with pharmacological, chemical or physical stimuli or allergens, and on the rate of change of lung volumes, than on the relationship of an isolated result to published "normative data". In fact, the best reference value is the value observed in a period when the disease is stable and minimal for that person. In studies such as the effects of drugs in patients with lung disease, or of adverse effects of environmental factors on the lungs, observed values should not be compared with reference values; instead, a comparison should be made with values obtained in an appropriately chosen control group.

\section{Purpose of review}

\subsection{General considerations}

Reference values should derive from studies employing standardized procedures and equipment. Whilst recommendations have been published previously [1-3], they do not encompass the whole age range from birth to old age for all techniques. On that account, under the aegis of the American Thoracic Society, a workshop on Lung Volume Measurements (co-chairs: J.L. Clausen, A.L. Coates, Ph.H. Quanjer) was organized. This paper 
was developed as a background document for the workshop, and also reflects input from workshop discussions; background papers for other aspects of lung volume measurements will be published subsequently, as will a consensus document reflecting the final consensus recommendations from the workshop.

The purpose of this paper is not to produce details of all the published prediction equations for static lung volumes, many of which have been summarized previously $[1,2]$, but to: 1) highlight the limitations in currently available reference data and their application; 2) provide broad recommendations regarding the selection and use of such reference data, bearing in mind the potential limitations; 3) suggest how prediction equations for lung volumes could be improved in the future; and 4) discuss areas of controversy, which need to be resolved to facilitate more appropriate use of such equations.

Many of the problems associated with the establishment and use of reference values are common to all indices of lung function throughout life. However, the additional difficulties incurred in recruiting and studying healthy infants and young children result in there being relatively few data available for subjects less than 5 yrs of age. Consequently, whereas it should be possible to develop similar recommendations for use in adults and older children, those pertaining to infants and preschool children need to be dealt with separately. Similar problems apply to old age, an area neglected in lung function testing [3].

\subsection{Background}

In the various publications that have stressed the need to standardize nomenclature, equipment and procedures to be used for performing pulmonary function tests, relatively little emphasis has been placed on the need to adopt a more standardized approach to the use of reference values and interpretation of lung function tests [4].

Unfortunately, although there are numerous publications of so-called "reference values" for lung volumes $[1,5]$, many result in appreciable differences in predicted values at any given age or body size, and relatively few guidelines exist to assist the researcher or clinician in the appropriate selection and use of reference values. Furthermore, there is controversy with regard to the level of dysfunction which should be considered abnormal, and what constitutes a real change with time.

The establishment and interpretation of reference values for respiratory function and the associated concepts of "normality" have been discussed in detail in several review articles [1, 4, 6-9]. The application of reference standards for lung volumes, in common with other indices of lung function, may be fraught with difficulties if: 1) standards derived from cross-sectional data are applied to longitudinal studies; 2) characteristics of the reference population differ from those of the sample being studied with respect to age, body size, sex or ethnic origin; 3) methods and techniques used in a study differ from those applied when establishing the reference values; or 4) criteria for identifying the "normal range" have not been established.
The most important determinants of lung volume are body size, sex and age, and the usual approach is to use some combination of these attributes when predicting lung volume [1-3, 7]. However, during recent years, there has been increasing evidence of ethnic [3, 10-15] and environmental influences (e.g. passive smoking), which also need to be borne in mind, together with the potential effects of puberty. Lung growth appears to lag behind the increase in standing height during the growth spurt $[16,17]$, and there is evidence that developmental stage may be an important determinant of lung function, as evidenced by the shift in relationship between lung volume and height during adolescence [16, 18]. It is generally accepted that TLC does not change with ageing in healthy adults, but residual volume (RV) increases in an approximately linear fashion; age dependence of functional residual capacity (FRC) in adults is inconclusive [5].

During infancy and childhood, the rate of somatic growth is extremely rapid, especially during the first year of life and during adolescence. Appropriate statistical modelling to take alinearity of various growth spurts [18] or nonlinear change in ventilatory function with ageing into account may increase the sensitivity of lung volume measurements in the early detection of reduced lung function. Such an approach will be facilitated by the use of longitudinal, rather than cross-sectional, studies $[16,19$, 20]. Whilst the availability of increasingly powerful computers and statistical software makes it possible to calculate reference values by endless permutations of regression models, these do not always have an obvious biological meaning, and the underlying assumptions of the model (e.g. normality of distribution when applying linear regression equations) have not always been adequately tested.

\section{Published reference values}

\subsection{Reference values in infants}

The only lung volume that can be measured routinely with accuracy and reliability in infants is FRC, although attempts have been made to assess TLC from measurements of crying vital capacity and RV [21-25]. A large number of studies have reported values for FRC in healthy infants using both helium dilution [23, 26-33] and plethysmographic techniques [34-43]. Many of these studies have confined measurements to the neonatal period, thereby precluding calculation of prediction equations based on body weight or length. In such studies, lung volume has frequently been expressed per kilogram body weight, which may be valid during the first month of life, when the regression of volume on weight appears fairly linear and passes close to the origin. Using this approach, there has been reasonable agreement between the mean values of FRC $\left(\mathrm{ml} \cdot \mathrm{kg}^{-1}\right)$ in newborn infants published from various studies, being approximately 23 $\mathrm{ml} \cdot \mathrm{kg}^{-1}$ when using the helium dilution technique [27, $32,44]$ and $32 \mathrm{ml} \cdot \mathrm{kg}^{-1}$ from plethysmographic measurements $[27,37,39,40]$. However, this does not reflect 
the wide scatter of results observed within many of the studies, which must be borne in mind when interpreting results. The discrepancy between gas dilution and plethysmographic techniques has been largely attributed to the presence of trapped gas, which is not detected by gas equilibration methods [45-48]. However, there have been relatively few high quality comparative studies on sufficiently large numbers of infants to clarify this issue.

Of the studies which have measured FRC in infants during the first year of life, relatively few have included more than 50 individuals. However, there is remarkable consistency between predicted values based on data published by DoERshuk et al. [36] (though only four subjects $<70 \mathrm{~cm}$ were studied), Phelan and Williams [41], Hatch and TAYLOR [38] and Stocks and GodFrey [43], using the plethysmographic technique; and between HANRAHAN et al. [28] and TEPPER and co-workers $[31,33]$ when using the helium dilution technique. Values predicted by GAULTIER et al. [23] are consistently higher; whereas, those of TAUSSIG et al. [30] are somewhat lower in younger infants but higher in older infants. These discrepancies may be partially attributed to the wider age range studied both by Gaultier and Taussig, with relatively few infants being studied during the first year of life. Prediction equations from most of these studies have been based on simple linear regression, and may benefit from a more stringent approach (see "Reference values in adults").

Despite recently renewed interest in the nitrogen washout technique, particularly with respect to its application in the intensive care unit [49], very limited data are available for healthy infants and children $[47,50]$. GERHARDT et al. [51] studied 50 children over the first 5 yrs of life (14 of whom were less than 1 month old), and found a high correlation between FRC and body length. However, predicted values were considerably lower than those found either by plethysmography or helium dilution (i.e. 126 $\mathrm{ml}$ for a child of $70 \mathrm{~cm}$ crown-heel length), and the confidence intervals were extremely wide, particularly for older children, reflecting the small numbers over a wide age range. However, more recent evidence suggests that, when both measurements are made in the same infants, the nitrogen wash-out method and helium dilution techniques yield similar values of FRC [52].

In an attempt to produce more reliable prediction equations, data from several different centres, in which: 1) at least 25 healthy Caucasian infants have been studied; 2) all raw data and details of methodology are available; and 3) data are representative of those published elsewhere in the literature, have been collated. Details of these studies are given in table 1 . Only one result (randomly selected) was included for those infants in whom sequential measurements had been performed. Because of the known discrepancies according to methodology [48], separate equations were calculated for $\mathrm{FRCHe}$ and FRCpleth.

Data on FRCHe were available from 378 infants, the majority of whom were studied in the first 18 months of life. Although a large proportion of variance is explained by body size (fig. 1), simple linear regression of FRC on either weight or length was found to be inadequate,
Table 1. - Details of selected infant studies

\begin{tabular}{lccrccc}
\hline $\begin{array}{l}\text { First } \\
\text { author }\end{array}$ & Year & [Ref.] & $\begin{array}{c}\text { Sub } \\
\mathrm{n}\end{array}$ & $\begin{array}{c}\text { Weight } \\
\mathrm{kg}\end{array}$ & $\begin{array}{c}\text { Length } \\
\mathrm{cm}\end{array}$ & $\begin{array}{c}\text { Age } \\
\text { month }\end{array}$ \\
\hline TEPPER* & 1986 & 31 & 111 & $1.6-13.1$ & $44-80$ & $0.0-13$ \\
HANRAHAN* & 1990 & 28 & 120 & $3.2-16.0$ & $48-88$ & $0.2-18.9$ \\
TEPPER* & 1992 & 33 & 110 & $2.6-14.2$ & $48-89$ & $0.1-31$ \\
Merth* $^{*}$ & 1993 & Unp. & 37 & $1.9-10.3$ & $45-78$ & $0.1-16$ \\
DOERSHUK $^{+}$ & 1969 & 37 & 49 & $2.5-5.1$ & $46-54$ & $0.0-0.1$ \\
DoERSHUK $^{+}$ & 1970 & 36 & 25 & $4.1-14.3$ & $54-85$ & $1-23$ \\
PHELAN $^{+}$ & 1969 & 41 & 25 & $3.6-9.0$ & $52-72$ & $1-10.6$ \\
HATCH $^{+}$ & 1976 & 38 & 35 & $5.0-12.9$ & $58-83$ & $4-16$ \\
STOCKS $^{+}$ & 1977 & 43 & 48 & $1.3-12.0$ & $40-84$ & $0.1-12$ \\
Dezateux $^{+}$ & 1992 & Unp. & 107 & $3.6-11.8$ & $52-84$ & $1.1-15$ \\
\hline
\end{tabular}

*: helium dilution; +: body plethysmography. Unp.: unpublished; Sub: subjects.

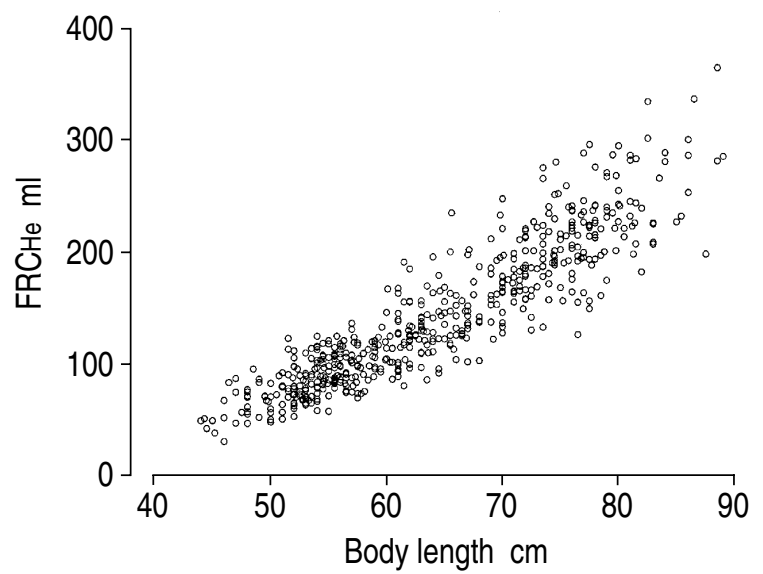

Fig. 1. - Functional residual capacity assessed in infants by helium dilution method (FRCHe). Data derived from studies in table 1.

in view of the heteroscedastic scatter of the residuals around the regression. Logarithmic transformation stabilized the variance, $\log _{\mathrm{e}}(\mathrm{FRCHe})$ regressed on $\log _{\mathrm{e}}$ (length) providing the best model (table 2). There were no significant differences between the four laboratories supplying these data.

Modelling for FRCpleth proved to be more complex (fig. 2). Data from preterm infants $(<2.5 \mathrm{~kg}$ birthweight and $<36$ weeks gestational age) were excluded because of differences in their FRCpleth in relation to length and weight. LogFRCpleth regressed against log length and log weight gave a reasonable description of the data. Although there were significant differences between laboratories, there was no interaction between laboratory

Table 2. - Proposed preliminary prediction equations for FRC (in $\mathrm{ml}$ ) in infants and young children

\begin{tabular}{llcrl}
\hline Index & Equation & RSD & $90 \%$ CI & $95 \%$ CI \\
\hline FRCHe & $0.0036 \cdot \mathrm{L}^{2.531}$ & 0.177 & $75-134 \%$ & $71-144 \%$ \\
FRCpleth & $2.36 \cdot \mathrm{L}^{0.75} \cdot \mathrm{W}^{0.63} \cdot \mathrm{k}$ & 0.140 & $79-126 \%$ & $76-132 \%$
\end{tabular}

L: crown-heel length $(\mathrm{cm})$; $\mathrm{W}$ : body weight $(\mathrm{kg}) ; \mathrm{k}$ : constant to describe laboratory interaction: $\mathrm{k}=1.0$ for data from Dezateux et al (unpublished) 1.01 from [36, 37], 1.07 from [38, 41, 43]. FRC: functional residual capacity; RSD: residual standard deviation; $95 \% \mathrm{CI}$ : $95 \%$ confidence interval. 


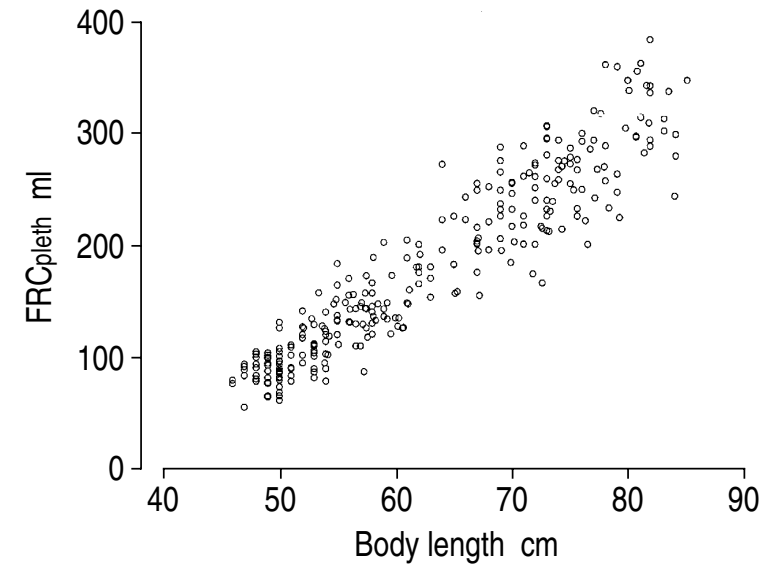

Fig. 2. - Plethysmographic measurements of functional residual capacity (FRCpleth) in infants. Collated data from the studies indicated in table 1 .

and log length or log weight. Predicted values needed to be increased by approximately $7 \%$ in order to adequately describe data collected by PHELAN and WiLliams [41], Hatch and Taylor [38] or StOcks and Godfrey [43]. At the present moment, the reasons for these discrepancies remain unclear, but could reflect the fact that, in contrast to FRCHe data, most of the FRCpleth data were published almost 20 yrs ago. Differences in methodology or apparatus may have resulted in more marked dynamic elevation of end-expiratory level in the earlier studies, whilst lack of equipment for measuring infants accurately could have resulted in some systematic underestimation of crown-heel length. Other factors which could contribute to the relatively smaller values of FRCpleth recorded during the largest and most recent study by Dezateux et al. (unpublished) include the increasing incidence of maternal smoking during pregnancy, and the fact that, in contrast to most previous studies which have used "hospital normals" as reference subjects, the study by Dezateux et al. recruited healthy infants from the community. These discrepancies highlight the need to test the proposed prediction equations (table 2) as widely as possible, and to use extreme caution when interpreting results with respect to "reference values".

Preliminary analyses revealed no differences according to gender for either technique using these collated data. Representative values of FRC at arbitrarily chosen lengths and weights are given in table 3 , where it can be seen that predicted values for FRCHe are consistently lower than those for FRCpleth throughout the first year of life. This discrepancy was reproduced in one study, in which paired measurements of $\mathrm{FRCN}_{2}$ and FRCpleth were performed in 11 healthy infants; the mean within-subject difference came to $3.9 \mathrm{ml} \cdot \mathrm{kg}^{-1}$ or $13 \%$ [48].

\subsection{Reference values in preschool children}

Reference values for preschool children (2-5 yrs of age) are even more limited than those in infants, with widely discrepant predicted values at any given length. Plethysmography is difficult to apply at this age, and measurements have, therefore, largely been confined to helium dilution [23, 30, 53-56]. Using this technique, mean predicted values may vary from 485 [55] to 736 $\mathrm{ml}$ [56] for a $100 \mathrm{~cm}$ child, and from 777 [30] to 1,240 $\mathrm{ml}$ [56] in a child whose height is $120 \mathrm{~cm}$.

Again, much of this discrepancy may be due to calculation of regression equations from relatively small numbers of children with uneven distribution over the age range, a criticism that can also be applied to many of the studies on older children. Differences in methodology, equipment, population and measurement conditions may be additional contributory factors.

By combining individual data collected in three different laboratories from 191 young Caucasian children (table 4), it is possible to extend the prediction equations for FRCHe from birth to 7 yrs of age $(125 \mathrm{~cm}$ height) (fig. 3). The resultant equation is remarkably similar to that derived for infants under 2 yrs of age, but does include a term which indicates significant differences between laboratories. Whether this discrepancy is due to differences in methodology, equipment or population has still to be determined, and further modelling to assess the potential influence of gender, weight, posture and

Table 4. - Details of selected preschool studies from which data have been collated to produce prediction equations for FRC

\begin{tabular}{lccrrr}
\hline $\begin{array}{l}\text { First } \\
\text { author }\end{array}$ & Year & [Ref.] & \multicolumn{1}{c}{$\begin{array}{c}\text { Sub } \\
\mathrm{n}\end{array}$} & \multicolumn{1}{c}{$\begin{array}{c}\text { Stature } \\
\mathrm{cm}\end{array}$} & \multicolumn{1}{c}{$\begin{array}{c}\text { Age } \\
\mathrm{yrs}\end{array}$} \\
\hline TAUSSIG & 1977 & 30 & 106 & $68-125$ & $1.5-6$ \\
GREENOUGH & 1986 & 53 & 32 & $87-120$ & $3-7$ \\
GREENOUGH & 1991 & 54 & 53 & $109-127$ & $5-8$ \\
\hline
\end{tabular}

For abbreviations see legend to table 2 .

Table 3. - Representative values (mean+95\% CI) of FRC at arbitrarily chosen values of length (supine) and body weight in infants, derived from collated data

\begin{tabular}{lccccc}
\hline Length cm & 50 & 60 & 70 & 80 & 90 \\
Weight kgף & 3 & 6 & 9 & 11 & - \\
\hline FRCHe ml & 72 & 114 & 168 & 236 & 318 \\
$95 \% \mathrm{CI} \mathrm{ml}$ & $51-102$ & $81-161$ & $119-237$ & $166-333$ & $226-448$ \\
FRCpleth ml & 89 & 157 & 228 & 286 & - \\
$95 \%$ CI ml & $68-117$ & $119-207$ & $173-301$ & $217-377$ & -
\end{tabular}

ף: only used for calculating FRCpleth; $\$$ : calculated from equation in table 2. For data collected prior to 1980, values may be approximately $7 \%$ higher. For abbreviations see legend to table 2 . 


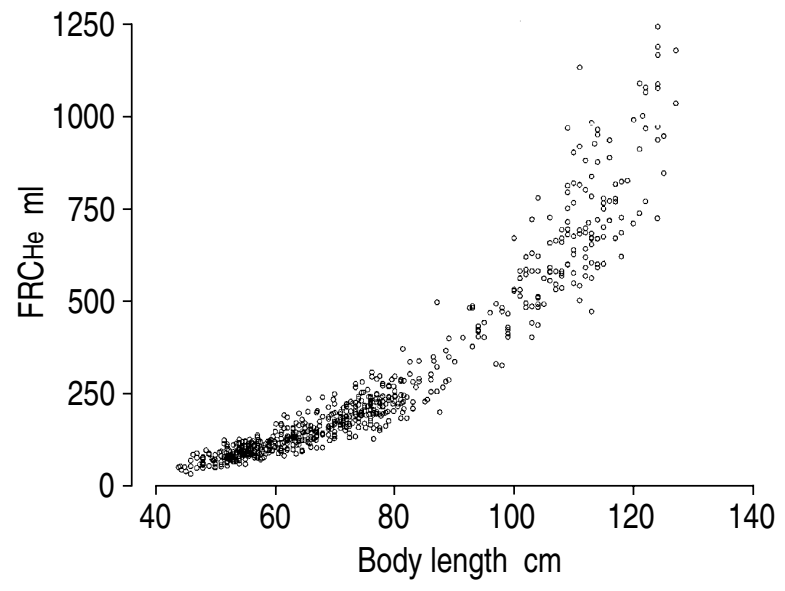

Fig. 3. - Functional residual capacity determined by helium dilution method $(\mathrm{FRCHe})$ in infants and preschool children. Individual data from the studies indicated in tables 1 and 4 have been combined. Note the increasing scatter (heteroscedasticity) as body dimensions increase.

age will be required, before prediction of FRC in preschool children can be made with confidence. However, a preliminary equation, which can be tested for this age range, is:

\section{$\mathrm{FRCHe}=0.0031 \cdot \mathrm{H}^{2.56} \cdot \mathrm{k}(\mathrm{RSD}=0.169,95 \% \mathrm{CI} 72-139 \%)$}

(FRC in $\mathrm{ml}, \mathrm{H}=$ height in $\mathrm{cm}$ ) where $\mathrm{k}=1.18$ for data reported by TAussig et al. [30] and GREENOUGH and coworkers [53], and 1.40 for more recent data from GREENOUGH and co-workers [54]. Representative values for $\mathrm{FRCHe}$ at various heights in young children are given in table 5 .

The relatively rapid increase in FRCHe beyond $90 \mathrm{~cm}$ (as reflected by predicted values that are $18-40 \%$ greater than those for infants) may, at least partly, reflect the fact that measurements in children over 3 yrs of age are generally performed in the sitting rather than supine position.

Of all the studies of FRC in infants and preschool children, only those by TAUSSIG et al. [30] and WALL et al. [56] have demonstrated significant differences due to gender; FRC in boys exceeding that in girls at any given length. Other studies, on larger numbers of infants over a narrower age range, have reported similar values in boys and girls [23, 28, 31, 55].

\subsection{Reference values in children and adolescents}

A large number of publications have reported reference values for RV, FRC and TLC in children of school

Table 5. - Representative values of $\mathrm{FRCHe}$ in young children at arbitrarily chosen heights, derived from [30, 53]*

\begin{tabular}{lcrccc}
\hline Index & Unit & \multicolumn{4}{c}{ Value } \\
\hline Height & $\mathrm{cm}$ & 90 & 100 & 110 & 120 \\
FRCHe & $\mathrm{ml}$ & 368 & 482 & 615 & 769
\end{tabular}

*: values based on [54] are about $18 \%$ higher. FRC: functional residual capacity.
Table 6. - Average values predicted according to various authors for lung volumes assessed by helium dilution [16, 57-66] and body plethysmographic [67-69] technique

\begin{tabular}{lrrrr}
\hline & $119 \mathrm{~cm}$ & $140 \mathrm{~cm}$ & $161 \mathrm{~cm}$ & $179 \mathrm{~cm}$ \\
\hline Boys & & & & \\
TLCHe ml & 1924 & 2990 & 4362 & 6284 \\
TLCpleth ml & 2172 & 3298 & 4680 & 6132 \\
FRCHe ml & 830 & 1330 & 2019 & 3082 \\
FRCpleth ml & 1060 & 1666 & 2427 & 3250 \\
RVHe ml & 403 & 626 & 905 & 1330 \\
RVpleth ml & 557 & 758 & 994 & 1230 \\
Girls & & & & \\
TLCHe ml & 1856 & 2866 & 4129 & 5891 \\
TLCpleth ml & 2106 & 3175 & 4494 & 5966 \\
FRCHe ml & 857 & 1332 & 2079 & 3144 \\
FRCpleth ml & 1036 & 1615 & 2338 & 3041 \\
RVHe ml & 436 & 630 & 915 & 1416 \\
RVpleth ml & 556 & 758 & 995 & 1232 \\
\hline
\end{tabular}

TLC: total lung capacity; FRC: functional residual capacity; RV: residual volume.

age, the majority of which have employed the helium dilution technique. Details of reference populations and regression equations have been summarized in a recent report [1], where it can be seen that equations have frequently been derived from relatively small populations ( $<200$ children) over a $6-12$ yr age range, when growth and developmental changes are extremely rapid. A survey of predicted values at various standing heights, according to various authors, is given in table 6. Boys tend to have a larger TLC than girls. The influence of ethnic differences has been shown, with lung volumes being larger in Caucasian than black children [70]. This has been largely attributed to differences in trunk:leg ratios $[11,13]$, although ethnic differences in chest wall dimensions may also be a contributory factor [12].

Relatively few of the published studies have taken puberty or age into account, although the significance of these factors has been stressed in more recent publications [16-18], as has the need to interpret results with respect to longitudinal rather than cross-sectional data, if the effects of growth and temporal changes are to be properly accounted for $[19,20,71-74]$. There is no evidence for a cohort effect in ventilatory function in the paediatric age range [75].

Recent questionnaires [76-78] have shown that, despite the large number of reference equations available in the literature, surprisingly few are actually used. The majority of centres in North America have been using equations published by Polgar and Promadhat [79], Weng and Levison [61] or CoOK and Hamann [58]. Only 58\% of centres were correcting for ethnic differences, and then usually in the form of a fixed proportional reduction in Caucasian based equations rather than by using population specific regression equations, as endorsed by the GAP conference committee [80]. The data of CoOK and HAMANN cover the largest age range (5-38 yrs) and are a representative mean of the other predictions; they also appear to agree reasonably well at the transition between 


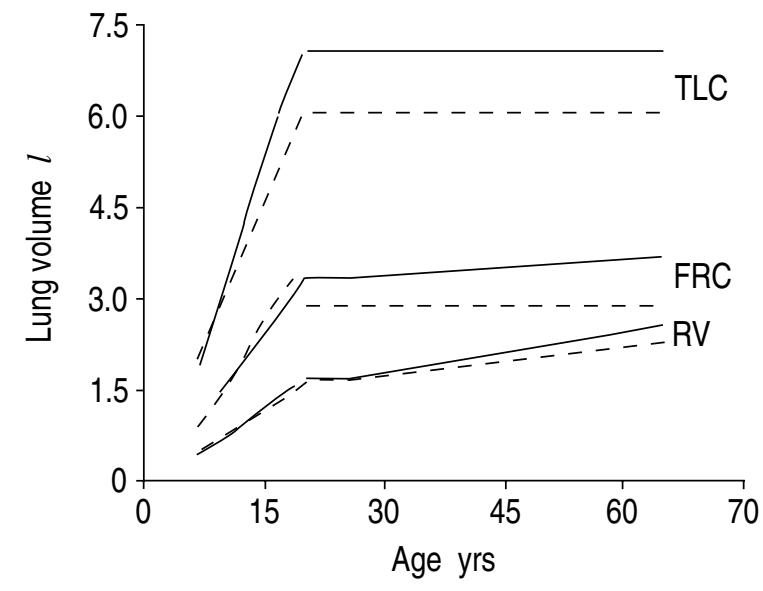

Fig. 4. - Lung volumes as a function of age. Predictions in adults are due to the ECSC [3] and apply to a person of $1.79 \mathrm{~m}$, those in children and adolescents (ultimate stature in this illustration $1.79 \mathrm{~m}$ ) are due to CoOK and HAMANN [58]. TLC: total lung capacity; FRC: functional residual capacity; RV: residual volume; ECSC: European Community for Steel and Coal. _—: males; - - -: females.

adolescence and adulthood, except for FRC in girls (fig. 4 ), and at the other end fall midway between the quoted values for preschool children (table 5). The regression equations of WENG and LEVISON [61] are less acceptable, predicted values for girls and boys are the same, which is unrealistic, and do not connect smoothly to predictions in adults. The values obtained by gas dilution technique are consistently lower than those obtained by body plethysmography, as in infant studies (see "Refe-rence values in infants"). Therefore, until more studies are available using modern techniques, the predictions of CoOK and Hamann [58] are suggested for use in the age range 5-18 yrs for gas dilution methods, and those of ZAPLETAL et al. [68] for plethysmographic data (table 7), with the following cautionary notes:

1) Single equations spanning this age range are likely to predict volumes which tend to be too low both at the lowest and highest ages, and too high prior to the adolescent growth spurt. Thus, lung volumes in a young child are likely to move gradually to lower percentiles prior to the growth spurt, and again to higher percentiles from adolescence to adulthood [16, 18, 81, 82]; this should be taken into account when interpreting longitudinal data in an individual. More work is needed [16, 73] to establish appropriate reference values over the whole age range.

2) The predictions were derived from a Caucasian population. Factors to take ethnic group into account are the same as those recommended for adults (see "Reference values in adults").

3) At the start of adulthood, there will be discontinuities when moving to predictions for adults (fig. 5). This can only be remedied by establishing reference values in the future which are continuous from birth to old age.

Very few direct comparisons have been made of FRC obtained in children by body plethysmography and gas dilution. Cogswell et al. [84] compared the two measurements in 225 healthy children between 5-15 yrs and found that FRCpleth exceeded FRCHe by $130-320 \mathrm{ml}$ (mean $206 \mathrm{ml})$ for every height group $(110-180 \mathrm{~cm})$ both
Table 7. - Prediction equations for lung volumes according to CooK and Hamann [58] (gas dilution method) and ZAPLETAL et al. [68] (body plethysmographic technique) recommended for use in children and adolescents

\begin{tabular}{lllll}
\hline Volume & Equation & $90 \%$ CI & $95 \%$ CI & RSD \\
\hline Gas dilution & & & & \\
Boys & & & & \\
TLC ml & $0.95 \cdot 10^{-3} \cdot \mathrm{H}^{3.039}$ & $83-120$ & $81-124$ & 0.104 \\
FRC ml & $0.125 \cdot 10^{-3} \cdot \mathrm{H}^{3.298}$ & $77-130$ & $73-137$ & 0.148 \\
RV ml & $0.162 \cdot 10^{-3} \cdot \mathrm{H}^{3.099}$ & $64-156$ & $59-170$ & 0.239 \\
Girls & & & & \\
TLC ml & $1.698 \cdot 10^{-3} \cdot \mathrm{H}^{2.909}$ & $76-132$ & $72-140$ & 0.157 \\
FRC ml & $0.286 \cdot 10^{-3} \cdot \mathrm{H}^{3.136}$ & $76-148$ & $62-160$ & 0.215 \\
RV ml & $0.32 \cdot 10^{-3} \cdot \mathrm{H}^{2.972}$ & $59-169$ & $53-187$ & 0.278 \\
Plethysmography & & & \\
Boys & & & & \\
TLC ml & $9.96 \cdot 10^{-3} \cdot \mathrm{H}^{2.5698}$ & $90-111$ & $88-113$ & 0.064 \\
FRC ml & $3.22 \cdot 10^{-3} \cdot \mathrm{H}^{2.6523}$ & $87-116$ & $84-119$ & 0.088 \\
RV ml & $21.06 \cdot 10^{-3} \cdot \mathrm{H}^{2.1314}$ & $73-137$ & $69-145$ & 0.191 \\
Girls & & & & \\
TLC ml & $9.17 \cdot 10^{-3} \cdot \mathrm{H}^{2.5755}$ & $87-115$ & $85-118$ & 0.083 \\
FRC ml & $3.70 \cdot 10^{-3} \cdot \mathrm{H}^{2.6149}$ & $82-123$ & $78-127$ & 0.124 \\
RV ml & $21.06 \cdot 10^{-3} \cdot \mathrm{H}^{2.1314}$ & $73-137$ & $69-145$ & 0.191 \\
Boys and girls & & & \\
FRC\%TLC* & 45.6 & $36-55$ & $34-57$ & 5.7 \\
RV\% TLC* & 21.7 & $12-31$ & $11-33$ & 5.7 \\
\hline
\end{tabular}

$\mathrm{H}$ : stature in $\mathrm{cm}$; $\mathrm{CI}$ : confidence interval in percentage predicted; RSD: residual standard deviation on a logarithmic scale, taking the natural logarithm. For further abbreviations see legend to table 6. *: collated data [83].

in males and females. This is similar to the mean difference noted between techniques when comparing results from separate studies (table 6). By contrast, KRAEMER et al. [85] found no significant differences between measurements of FRC using plethysmography, nitrogen washout and helium dilution in 54 children, aged 7-17 years.

Despite increasing interest, reliable reference values for lung volumes in infants and children have yet to be established when using radiographic [86], echoplanar [87], or other imaging techniques.

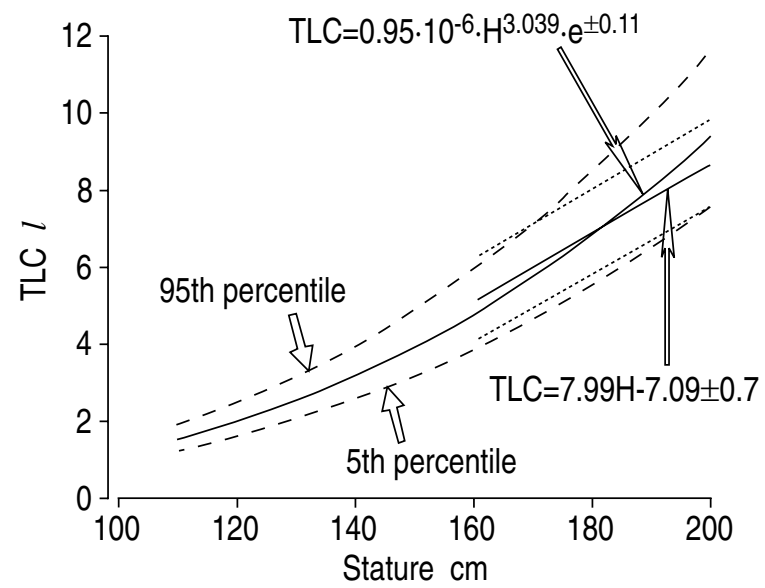

Fig. 5. - Comparability of predicted TLC and confidence limits in boys [58] and in adult males [3]. Note that in children and adolescents, unlike adults, the scatter is proportional to the predicted value. TLC: total lung capacity; $\mathrm{H}$ : height. 


\subsection{Reference values in adults}

Ideally, reference values should be derived from persons with no known previous or present conditions that adversely affect their ventilatory function. This is an idealistic starting point, because passive smoking, occupational exposure, and childhood respiratory infections may all affect lung volumes, and strict application of exclusion criteria means that only a small proportion of a normal population meets the criteria; in particular, only few elderly subjects can satisfy the requirements. Lung volumes are also considerably influenced by the amount of body fat: gross obesity decreases total and chest wall compliance [88, 89], and thus diminishes expiratory reserve volume and FRC [90-94]. Hence for practical purposes, adults from whom reference values are derived should be asymptomatic lifelong nonsmokers, with no past or present respiratory disease which may affect lung function, and have a normal body composition (i.e. within the 5 and 95 percentiles, taking into account ethnic group).

In order to satisfactorily account for the influence of age, stature, body mass and other factors that may determine lung volumes in healthy adults, it is desirable that the reference population is large, ideally more than 100 adults, for men and women, for the various ethnic groups, and with an even distribution with respect to age. No studies are available from the literature which satisfy all of the above requirements [2]. Hence, further studies are required which can provide such reference values. A survey of published studies is given in [2]; the selection is limited to studies on asymptomatic subjects who have been studied by gas dilution techniques and by body plethysmography. Current smokers and ex-smokers were not, as a rule, excluded; in addition, the studies are confined to Caucasian subjects, leaving other ethnic groups uncovered. Reports of plethysmographic studies frequently do not clarify whether corrections were made if airway occlusions were not performed exactly at FRC, how many measurements were performed, and what quality criteria were applied. Similarly, there is uncertainty in most studies regarding how TLC was obtained, and the quality criteria in gas dilution measurements. Finally, since most of the studies were performed at least two decades ago, they may not meet present day quality criteria. In addition, they may not fit present day populations due to cohort effects [95-99].

Thus, published reference values are unsatisfactory by today's standards. Discrepancies between predictions for either men or women for the various indices are very large [2]; these are likely to reflect differences in the technique applied, in quality control and in selection of subjects [2]. This implies that none of the studies can at present be singled out as superior to the others, or as representative of different populations. A working party of the European Community for Steel and Coal (ECSC) argued that the merit of adopting the same set of reference values in different laboratories was that this allowed comparison of results obtained in various laboratories; they derived summary equations [2] from published reference equations using the technique previously applied by Polgar and Promadhat [79]. This process of arriving at predictions is not ideal, because the procedure is not based on original data (these were no longer available) but on published regression equations, which may not have been the best description of the data. However, the prediction equations for various indices (table 8), which have been endorsed by the European Respiratory Society [3], are provisionally adopted here, as they have been shown to apply well to Caucasian populations [9, 100-104]. Pending more satisfactory data, the summary equations may be used with the following provisos:

1) The data on TLC, RV and FRC derive from populations which include smokers and ex-smokers, so that both the mean predicted value and the scatter around the mean may not be representative of a nonsmoking healthy population. On that account, the value for RV in healthy nonsmokers may be smaller than the predicted one. In healthy adults, plethysmographic and gas dilution methods have been shown to give the same results [105-107], so that the reference values for $\mathrm{FRCHe}$ and FRCpleth are the same.

2) The equations apply to a height range of $1.55-1.95 \mathrm{~m}$ in men, and $1.45-1.80 \mathrm{~m}$ in women. They are applicable between ages 18-70 yrs. Between 18-25 yrs an age of $25 \mathrm{yrs}$ should be substituted in the equations, to account

Table 8. - Reference values for lung volumes in adults [3]

\begin{tabular}{|c|c|c|c|c|}
\hline Volume & Equation & $95 \% \mathrm{CI}^{*}$ & $90 \% \mathrm{CI}^{*}$ & RSD \\
\hline \multicolumn{5}{|l|}{ Males } \\
\hline TLC $l$ & 7.99·H-7.08 & \pm 1.37 & \pm 1.15 & 0.70 \\
\hline $\mathrm{RV} l$ & $1.31 \cdot \mathrm{H}+0.022 \cdot \mathrm{A}-1.23$ & \pm 0.67 & \pm 0.80 & 0.41 \\
\hline FRC $l$ & $2.34 \cdot \mathrm{H}+0.01 \cdot \mathrm{A}-1.09$ & \pm 0.99 & \pm 1.18 & 0.60 \\
\hline FRC/TLC \% & $43.8+0.21 \cdot \mathrm{A}$ & \pm 13.2 & \pm 11.1 & 6.74 \\
\hline RV/TLC \% & $14.0+0.39 \cdot \mathrm{A}$ & \pm 10.7 & \pm 9.0 & 5.46 \\
\hline \multicolumn{5}{|l|}{ Females } \\
\hline TLC $l$ & $6.60 \cdot \mathrm{H}-5.79$ & \pm 1.18 & \pm 0.99 & 0.60 \\
\hline $\mathrm{RV} l$ & $1.81 \cdot \mathrm{H}+0.016 \cdot \mathrm{A}-2.00$ & \pm 0.58 & \pm 0.69 & 0.35 \\
\hline FRC $l$ & $2.24 \cdot \mathrm{H}+0.001 \cdot \mathrm{A}-1.00$ & \pm 0.82 & \pm 0.98 & 0.50 \\
\hline FRC/TLC \% & $45.1+0.16 \cdot \mathrm{A}$ & \pm 11.6 & \pm 9.8 & 5.93 \\
\hline RV/TLC \% & $19.0+0.34 \cdot \mathrm{A}$ & \pm 11.4 & \pm 9.6 & 5.83 \\
\hline
\end{tabular}

*: Lower and upper 2.5 and 97.5 , or 5 and 95 percentile. Percentiles are obtained from predicted \pm value shown. A: age in yrs; $\mathrm{H}$ : stature in metre. For further abbreviations see legends to tables 2 and 6. 
for the transitional plateau phase between lung growth and decline with ageing.

The size of the lungs varies with ethnic group [14, 15]. This is, in part, explained by differences in trunk length relative to standing height, but also to differences in fat free mass, chest dimensions, and the power of respiratory muscles.

There is a remarkable lack of data on static lung volumes in non-Caucasians. In blacks, in the United States, the subdivisions of lung volume expressed as a proportion of the TLC appear to be the same as in whites (this applies also to $\mathrm{FEV}_{1} \% \mathrm{TLC}$ ), but $\mathrm{RV}, \mathrm{VC}$ and TLC are, on average, $12 \%$ lower than in whites [108]; this difference may be smaller in elderly persons than in young adults [109]. However, in one large study of roentgenographically determined total lung capacity, RV\%TLC was different between blacks and whites [110]. Based on trends in the FVC, it is likely that lung volumes in Polynesians, Northern Indians and Pakistanis are 10\% smaller than in Caucasians [3]. In Southern Indians and those of African descent, lung volumes are about 12-13\% smaller than in Caucasians. The lung size of a person of mixed racial origin is intermediate between that of the parents [10].

\section{Recommendations}

\subsection{Selecting reference values}

Reference values for use in any laboratory may be obtained by: 1) selecting an appropriate published set of values; 2) establishing specific reference values for that laboratory; or 3) combining data from several laboratories, in which a standardized approach to techniques, methods of analysis, and characteristics of the reference population has been adopted.

4.1.1 Selection of appropriate published reference data. When selecting a published set of reference data, it is important to check that:

1) The characteristics of the reference population represent a healthy population, and are matched to those of the study group with respect to age and body size, sex, racial and ethnic mix, and, if possible, to nutritional and socioeconomic background and environmental aspects (e.g. pollution, altitude etc.).

It is particularly important to avoid any extrapolation of regression equations beyond the size and age range of subjects actually studied.

For practical purposes, the following recommendations, modified from the GAP conference [80], may be adopted; whereby, a healthy person is defined as one in whom there is: 1) no presence of acute and no past chronic disease of the respiratory system; 2) no major respiratory disease, such as congenital anomalies, destructive type of pneumonia or thoracic surgery in past medical history; 3) no systemic disease which may directly or indirectly influence the respiratory system and general state of health (e.g. cardiovascular, neuromuscular, skeletal or renal disease); 4) no history of upper respiratory tract infection during 3 weeks prior to investigation.

Additional features include: 5) normal body composition (weight within 5 and 95 percentile for height, taking into account ethnic group).

In children: 6) no more than incidental smoking experience.

In infants: 7) gestational age at least 37 weeks, and birthweight at least $2.5 \mathrm{~kg} ; 8$ ) no history of other than transient respiratory problems during the neonatal period (less than $24 \mathrm{~h}$ with fractional inspiratory oxygen $\left.\left(\mathrm{FIO}_{2}\right)>0.3\right)$.

In adults: 9) lifelong nonsmokers, or no more than incidental smoking experience.

Some authors have suggested more stringent criteria for defining "health" [20] (see "Controversies").

Rationale. There is clear evidence for the influence of sex, ethnic origins and age/developmental stage as determinants of lung volume in school age children and adults [1, 3, 12-16, 20, 54, 70, 111], which should not be ignored. Whilst the significance of these factors in preschool children and infants has yet to be clarified, appropriate matching with regard to published reference values would be a wise precaution. Potential effects of preterm delivery on subsequent lung growth have not been clearly established, but, since this could be an important determinant of lung function, results from preterm and full-term infants should ideally be analysed separately.

It is important to inspect scattergrams of raw data from published studies to assess the exact range and distribution of measurements with respect to age or size. Many studies have an apparently appropriate age range, but with so few subjects at either extreme that calculation of reliable predictive values and confidence intervals becomes very difficult.

Longitudinal studies analysed by appropriate statistical models are necessary to correctly describe the growth of an individual and the functional changes associated with ageing. Analysis of longitudinal lung function data is complicated by missing data, variable follow-up time, information from co-variates, and the possibility of alinearities during the growth process and during ageing. However, these potential problems can be overcome by appropriate statistical modelling of the growth of lung volumes and height in healthy children and adolescents, as well as age-related decline in adults, thereby allowing more rapid detection of the onset of abnormalities than if analysis is based on cross-sectionally derived percentiles $[19,20,71,112,113]$.

2) Similar equipment, techniques, measurement conditions and analytical approaches have been used in the selected reference population as in the current study.

Rationale. Whilst the causes of discrepancies are not fully understood, there appear to be significant differences between absolute lung volumes in young children according to technique applied - especially in infants. Differences in sleep state, equipment, technique, methods of analysis (including computer software [114]), 
reproducibility and criteria for acceptability may all introduce bias when interpreting results [7, 28, 30, 83]. Although the gas dilution techniques and body plethysmography yield very similar results in adults [105-107], reference values derived from the two techniques cannot be used interchangeably in infants, in whom there is clear evidence of discrepancies, with plethysmography derived values being $13 \%$ greater than those obtained using nitrogen dilution [48]. Interestingly, discrepancies of a similar magnitude appear to persist throughout childhood (tables 6 and 7).

3) Assumptions underlying the statistical model used for calculating the prediction equation should be valid and biologically meaningful.

Rationale. The majority of prediction equations have been calculated by the traditional linear regression equation method, a model first described by HuTCHINSON [115] in 1846 , which remains very popular - primarily on account of its simplicity. In cross-sectional studies of adults, this model (of the form: volume $=\mathrm{a}+\mathrm{b} \cdot \mathrm{H}+\mathrm{c} \cdot \mathrm{A}$ $\pm \mathrm{RSD}$, where $\mathrm{H}=$ height, $\mathrm{A}=$ age, and $\mathrm{RSD}=$ residual standard deviation, i.e. the scatter around the predicted mean which is left after taking into account variability due to stature and age) appears to be valid, except at extreme combinations of age and height [116]. In the paediatric age range, linear regression of untransformed values of lung volume on height is not justified: firstly the relationship is not linear; and, secondly, the scatter is not normally distributed around the predicted, but increases in proportion (heteroscedastic) to the predicted value (figs $1-3$ and $5,[1,117])$. A predictable exception is when studies cover such a small age range that nonlinear relationships easily go unnoticed. Thus, transformations are required which both "stabilize the variance" and linearize the relationship. This is almost invariably achieved by logarithmic transformation of volume, or of volume and height. The relationships are then studied by linear regression on $\log$ transformed data [1], i.e. either $\ln$ (volume) $=\ln (\mathrm{a})+\mathrm{k} \cdot \ln ($ height $) \pm \mathrm{RSD}$, or $\ln ($ volume $)=\ln \mathrm{a}+$ $\mathrm{k} \cdot$ height $\pm \mathrm{RSD}$, where $\mathrm{ln}=$ natural logarithm. Thus, the predicted lung volume is either a power function of height $\left(\right.$ volume $=\mathrm{a} \cdot$ height $^{\mathrm{k}}$ ) or an exponential function of height (volume $=\mathrm{a} \cdot \mathrm{e}^{\mathrm{k} \text { height}) . ~ A ~ m o d e l ~ h a s ~ r e c e n t l y ~ b e e n ~ d e s c r i b e d ~}$ which appears to take account of the changing relationship between standing height and lung volume (FVC and $\mathrm{FEV}_{1}$ ) which occurs during the adolescent growth spurt [118]; this model (volume $=\mathrm{e}^{\mathrm{a}+(\mathrm{b}+\mathrm{c} \cdot \mathrm{A}) \cdot \mathrm{H}}$ ) merits study of its applicability to static lung volumes.

It is important to realize the difference between the relationships in adults and in infants, children and adolescents. In adults the scatter (RSD) around the predicted lung volume appears to be independent of the volume (homoscedastic), so that adults of different height and age in whom the observed lung volume is, e.g. one RSD higher than predicted, are comparable. However, in infants, children and adolescents, we have to exponentiate to obtain untransformed volume again, so that we have volume $=a \cdot h e i g h t^{k} \cdot e^{ \pm R S D}$ and volume $=a \cdot e^{k \cdot h e i g h t} \cdot e^{ \pm R S D}$, respectively; this illustrates the proportional nature of the scatter, as the predicted value is now multiplied by a fac- tor, rather than that factor being a constant amount which is added to or subtracted from any predicted value, as is the case in adults (table 8). It is convenient to take the natural logarithm, since, for small values the RSD can be interpreted in terms of percentages; thus, an RSD of 0.05 comes to about $5 \%$ above or below predicted as $\mathrm{e}^{0.05}=$ 1.05 , and $\mathrm{e}^{-0.05}=0.95$. Thus, the predicted TLC measured by plethysmography in a boy of $1.50 \mathrm{~m}$ (table 7) comes to $9.96 \cdot 10^{-3} \cdot 150^{2.5698}=3.89 \mathrm{l}$. The $\log _{\mathrm{e}}$ standard deviation from predicted comes to 0.064 (table 7); hence, values one times the RSD removed from the predicted mean come to $3.89 \cdot \mathrm{e}^{0.0688}$ and $3.89 \cdot \mathrm{e}^{-0.0688}$ or to 4.17 and $3.63 l$, respectively. With untransformed data, the range of reference interval given in absolute values may result in calculation of negative lower limits under certain circumstances, whereas this absurdity is impossible both in the proportional model and when predicting FRC and $\mathrm{RV}$ as a percentage of TLC.

4) Measurements are performed on a representative sample of healthy individuals over an appropriate age range, and compared with predicted results from the selected reference values.

Rationale. Application of a set of reference values to individuals with respiratory disease, without ensuring that they are appropriate for healthy individuals measured in the same laboratory using identical techniques, may result in severe bias when interpreting results. In adults, measured and predicted values can be compared directly by calculating the residuals (observed - predicted) for each subject. The reference equation producing the sum of residuals closest to zero will probably provide the best fit. In the paediatric age range, where nonlinear equations are used, comparison is slightly more complex, in that residuals are now $\log$ (observed) - $\log$ (predicted); this is because, in this age range, the scatter is proportional to the mean, and the log transformation removes this proportionality. Predicted values that are consistently inappropriate should lead to re-examination of both test technique and reference equation. This recommendation may be particularly difficult to implement in studies of infants and people of old age, due to the time-consuming nature of each test, and the limited availability of healthy elderly subjects and infants. However, the potential implications of uncritical application of reference values remain as important in any age group.

\subsubsection{Establishing specific reference values within a} laboratory. Potential problems in selecting appropriate published reference values, including the lack of standardized methodology and equipment, together with less than stringent criteria for defining the reference population, have persuaded several centres to develop specific reference values for use within a particular laboratory. Whilst this may overcome many of the potential errors associated with uncritical application of published reference values, it is a major undertaking, and there is a danger that too few subjects will be studied over an appropriate age range to provide a statistically acceptable sample group. Furthermore, it is difficult to compare results between different laboratories if different reference values 
are used. If this approach is adopted it is essential that: 1) measurements for reference values are performed in the same way as in daily routine, so that sources of variability will be the same; 2) periodic checks are performed to ascertain that quality of measurements remains the same; 3) recommendations with regard to characteristics of the reference population, statistical analysis and expression of results, as outlined above for the application of published reference values, are adhered to.

\subsubsection{Combination of data from several laboratories.} With the increasing use of standardized techniques and equipment, the best approach to providing improved reference values in the future may be to combine data from several laboratories. For this to be feasible, it is essential that agreement is reached with respect to: 1) characteristics of the reference population; 2) equipment and techniques (including anthropometric measurements); 3) reproducibility and criteria for acceptability; and 4) statistical modelling.

Rationale. Whilst summary equations have been produced, which give an overall mean of data from the literature $[2,79,119]$, their use should be temporary, as they are not derived from individual raw data; this makes it difficult to establish the best model and the true variability of reference values for calculation of standardized residuals, percentiles, etc. (see below).

Over the past $10 \mathrm{yrs}$, attempts have been made to collate individual data on lung volumes in infants, children and adolescents from various published sources, in an effort to produce more reliable prediction equations for this age group. With one exception [118], this proved to be an unsatisfactory approach, due to marked variability with respect to the characteristics of the reference populations and lack of standardized techniques, equipment and methods of analysis. A recent joint initiative by the European Respiratory Society and American Thoracic Society to standardize infant lung function testing [120] may largely resolve these difficulties and permit collation of prospective data, collected under standard conditions. Such an approach is particularly vital with respect to reference values in infants, where the timeconsuming nature of the tests limits the numbers which can be studied in any one laboratory. With such an approach, it may be possible to clarify the importance of factors, such as sex, race and premature delivery, as determinants of lung volume throughout the first years of life.

The collated data on FRC in infants (see "Reference values in infants"), as well as ongoing work on spirometric data collected in various European countries shows that, given that appropriate selection criteria, techniques and equipment have been used, there is much to be gained from combining, several studies. Therefore, investigators who have collected data according to present day standards are invited to submit their data to the authors to form part of a data bank managed by the European Respiratory Society. This data bank will be available for research purposes; in addition, in some decades from now it will make it possible to establish whether cohort effects affect ventilatory function.

\subsection{Expression of results}

1) It is recommended that, with the exception of the neonatal period, lung volumes should be expressed with respect to prediction equations based on body length or height as the major determinant (plus additional factors, such as age/developmental stage or age-height interaction where appropriate).

Rationale. In healthy children and infants, both height and weight may be equally good predictors but, beyond the neonatal period, length/height is preferable, provided it can be measured accurately, since it is less dependent on the relative undernourishment that may accompany many disease states, such as cystic fibrosis. Although length is a better predictor of lung volume in infants above 6 months of age, being less influenced by differences in body fat, it may be extremely difficult to measure accurately in newborn infants, especially on the intensive care unit. Consequently, both weight and length should be measured, whenever possible, so that either may be used as predictors during the neonatal period.

In young infants, lung volumes can be expressed per kilogram body weight, but this is not recommended beyond the first month of life. Lung volumes should never be expressed per centimetre body length. The use of ratios is only justified when one index varies linearly with the other and the relationship passes virtually through the origin. Since neither condition is met with respect to the relationship of lung volume on length, gross misinterpretation of the results is likely to occur due to calculation of false ratios if volumes are expressed as $\mathrm{ml} \cdot \mathrm{cm}^{-1}$ length $[121,122]$.

2) It is recommended that, in adults, the expression of lung volumes as "percentage predicted" is replaced or augmented by the use of standardized residuals or percentiles.

Rationale. The most frequently used method of expressing results is by percentage predicted (i.e. 100-observed/ predicted). This procedure is not valid in adults, because the scatter around the predicted value is constant, irrespective of the subject's height or age. Take two males, aged 25 and 60 yrs, stature 1.85 and $1.70 \mathrm{~m}$, respectively, in whom predicted values of RV (table 8) would be 1.33 and $1.91 l$, respectively, and in whom observed values for RV are 1.74 and $2.32 l$, respectively. Whereas the observed values in both individuals are one RSD above predicted (table 8 ), transformation to percentage predicted (i.e. $75 \%$ in the younger individual compared to $82 \%$ in the older) inappropriately suggests that their RVs are not comparable. However, the procedure is valid in children and adolescents [123], in whom the scatter is proportional to the mean (see above) (table 7).

Any cut-off point chosen to delineate "normal" from "abnormal" is necessarily arbitrary; usually, it is assumed that the scatter is normally distributed, when a lower 5 and upper 95 percentile (encompassing the $90 \%$ confidence interval) are obtained by calculating the predicted mean $\pm 1.64 \cdot$ RSD. Similarly, the $95 \%$ CI, which delineates the upper 97.5 and lower 2.5 percentiles (table 2 ) is obtained from the mean $\pm 1.96 \cdot \mathrm{RSD}$. The centiles may 
also be assessed empirically, making allowance for nonnormal distributions with changing standard deviations; this centile approach [124] may permit more appropriate and clinically useful interpretation of lung volume measurements, particularly in rapidly growing children and adolescents. It should be noted, however, that relatively large numbers of subjects are required for accurate calculation of such centiles. A practical disadvantage is that it is difficult to quantify the degree of abnormality and how far removed a result is from the normal population in the presence of severe disease. The recommended solution $[3,125,126]$ to this is to take the standardized residual, i.e. [recorded - predicted] divided by the RSD from the regression line; this provides a dimensionless index, indicative of how far the observed value is removed from the predicted, and thus the likelihood that such a value were to be observed in a healthy population. Standardized residuals should be used in evaluating lung function both in adults and children; however, in the latter they should be applied to log transformed data. Here are two examples of the use of the RSDS given in tables 7 and 8 . In an adult male of $1.8 \mathrm{~m}$ the predicted TLC is $7.29 l$, the observed value is $7.99 l$; hence, the standardized residual is $(7.99-7.29) / 0.70=1$, that is within the $70 \% \mathrm{CI}$ and, hence, comfortably within normal limits (table 9). In a girl of $1.70 \mathrm{~m}$ the predicted TLC is $5.23 l$, the observed value is $3.4 l$; the standardized residual is, therefore, $\left[\log _{\mathrm{e}}(3.4)-\log _{\mathrm{e}}(5.23)\right] / 0.157=$ -2.74. Therefore, her TLC is way below the range encountered in healthy girls of the same stature (table 9) and comes to $100 \cdot e^{-2.74 \cdot 0.157}=65 \%$ predicted. In a recent longitudinal study of healthy children and adolescents [19], the $95 \%$ confidence intervals for girls were $83-121 \%$ for TLC and 63-159\% for RV, with similar intervals for boys. This approach has also been implemented in infants [127].

\subsection{Measuring ancillary variables}

Age may be a useful predictor of lung function in addition to stature or body length. Whilst in adults it is acceptable to express age to the nearest full year, in infants and children, age should be accurate to two and one decimals, respectively, lest relative errors grow too large.

Standardized methods of measuring stature must be employed. In infants, this requires the use of a calibrated stadiometer and two trained adults. Repeat measurements should be within $0.5 \mathrm{~cm}$ of each other [128].

Table 9. - Value of standardized residual in relation to confidence interval (CI) in the case of normally distributed data (thus, $5 \%$ of observations would be less than predicted -1.644 .RSD, and $5 \%$ would be greater than predicted +1.644.RSD (see 90\% CI)

\begin{tabular}{|c|c|c|c|c|c|c|}
\hline $99 \%$ CI & 2.576 & $95 \%$ & CI & 1.960 & $60 \% \mathrm{CI}$ & 0.842 \\
\hline $98 \%$ CI & 2.326 & $90 \%$ & CI & 1.644 & $50 \% \mathrm{CI}$ & 0.674 \\
\hline $97 \%$ CI & 2.170 & $80 \%$ & CI & 1.282 & $40 \% \mathrm{CI}$ & 0.524 \\
\hline $96 \%$ CI & 2.054 & $70 \%$ & CI & 1.036 & $30 \% \mathrm{CI}$ & 0.385 \\
\hline
\end{tabular}

RSD: residual standard deviation.
Measurements in infants and toddlers should be made on the day of lung function assessment, as their length may increase overnight by more than one $\mathrm{cm}[129,130]$ due to saltatorial growth. Measurements of length should be made to the nearest millimetre or one half of a centimetre, since, particularly in infants, rounding to the nearest full centimetre introduces too large an error. Measurements of standing height should be made on the day of testing, with the subject on bare feet, standing up straight, so that heels, buttocks and shoulders are in contact with the vertical board of the stadiometer and the head aligned, such that the Frankfort plane is parallel to the floor; gentle pressure beneath the mastoid process should be applied to straighten the spine. The accuracy of stadiometers should be checked weekly [131].

\section{$4.4 \quad$ Future studies}

There is an urgent need to standardize techniques, equipment and methods of analysis, so that individual data from different laboratories can be collated in the future (see also [1]).

There is a need for further well designed longitudinal studies on infants and children, with special emphasis on the transition from infancy into childhood, during puberty and from adolescence into adulthood (18-25 yrs). Similarly, with the ever increasing proportion of elderly subjects in most societies, there is urgent need to establish reference values for elderly and aged persons. Statistical techniques should be applied which link data from different age groups smoothly.

Further studies are required which take the influence of sexual maturity on lung function into account. Before accurate prediction equations for non-Caucasians can be developed, it will also be necessary to establish when various ethnic groups mature.

Repeat studies of lung volumes are necessary, in view of the changing methodology; in addition, the secular trend for successive cohorts to grow taller appears to be associated with a changing ratio of leg to trunk length (established in Japan and Norway as cited in [132]), so that the relationship between stature and lung volumes is likely to be changing $[110,133]$.

\section{Controversies}

Areas of controversy, which need to be resolved before a standardized approach to the use of reference values and interpretation of lung volume data can be adopted, include:

Definition of health characteristics of reference population. The present recommendations, specified by a GAP committee [80] and adapted for infants and adults as necessary, are more or less in line with some previous recommendations $[1,7,8,134]$. They do no not take into account the potential influence on the lung of smoking during pregnancy, involuntary exposure to tobacco smoke in infants, toddlers and children, and of mild 
lower respiratory infections in infancy and childhood [135], or other more stringent criteria that would lead to defining "super health" [19]. For research, more stringent criteria for defining health than those adopted here seem warranted; for daily clinical practice, the present recommendations seem to be feasible and practicable.

Appropriate use of reference values in presence of skeletal abnormalities or severe growth retardation. In the case of spinal abnormalities, arm span may be used instead of standing height [66, 133, 136, 137]. The arms should be stretched horizontally against the ruler, when arm span is measured as the distance between the tips of the middle fingers and read to the nearest millimetre; the error in measurements is $0.5 \mathrm{~cm}$, comparable to that of stature [138].

Expression of results. There are as yet no validated prediction equations which span the whole age range from childhood to old age [7, 76-78, 123, 124, 126, 139, 140]. This often leads to large discontinuities in predicted ventilatory function, as subjects move from one age group to the next. With the advent of modern statistical tools, such as splines, this deficiency might be remedied.

Cross-sectional versus longitudinal data. Change in ventilatory function within an individual in time are often related to coefficients in regression equations. The latter are almost invariably obtained in cross-sectional studies; there, the results may be biased by selection effects (persons with the greatest decline in ventilatory function being least likely to survive to old age), and by cohort effects, so that the age or height coefficients are not representative of age-related changes within an individual. Thus, more research is needed to provide the tools with which to establish whether, in a growing or ageing individual, lung function develops normally. There is similarly a need to establish how to express changes in FRC and RV due to clinical interventions.

Consistency of reference values. In any data set predicting, e.g. FRC, from a straightforward regression equation, or from predicted FRC\%TLC multiplied by predicted TLC, leads to inconsistent results. These inconsistencies can only be avoided by predicting TLC, RV and FRC, and then deriving RV\%TLC and FRC\% TLC from these.

Acknowledgement: The authors acknowledge the assistance of C. Dezateux, R. Tepper and J. Hanrahan in collating the infant data. J. Stocks was supported by Portex Ltd.

\section{References}

1. Quanjer PhH, Stocks J, Polgar G, Wise M, Karlberg J, Borsboom G. Compilation of reference values for lung function measurements in children. Eur Respir J 1989; 2 (Suppl. 4): 184s-261s.

2. Quanjer PhH (ed). Standardized lung function testing. Report Working Party "Standardization of Lung Function Tests". Bull Eur Physiopathol Respir 1983; 19 (Suppl. 5): $1-95$.
3. Quanjer PhH, Tammeling GJ, Cotes JE, Pedersen OF, Peslin R, Yemault JC. Lung volumes and ventilatory flows. Report Working Party "Standardization of Lung Function Tests", European Community for Steel and Coal and European Respiratory Society. Eur Respir J 1993; 6 (Suppl. 16): 5-40.

4. American Thoracic Society. Lung function testing: selection of reference values and interpretation strategies. $\mathrm{Am}$ Rev Respir Dis 1991; 144: 1202-1218.

5. Quanjer PhH, Dalhuijsen A, van Zomeren BC. Reference populations: general data. Regression equations for reference values. In: Standardized Lung Function Testing. Report Working Party "Standardization of Lung Function Tests". PhH Quanjer (ed.). Bull Eur Physiopathol Respir 1983; 19 (Suppl. 5): 1-95.

6. Arcangeli P, Cotes JE. Normal values for respiratory function in man. Italy, Panminerva Medica, 1969;.

7. Buist AS. Evaluation of lung function: concepts of normality. Current Pulmonology. In: Simmons DH, ed. Boston, Houghton Mifflin, 1982; Vol. 4, Chp. 7.

8. Clausen JL. Prediction of normal values. Pulmonary Function Testing: Guidelines and Controversies. JL Clausen, ed. New York, London, Academic Press, 1982; pp. 49-59.

9. Quanjer $\mathrm{PhH}$. Interpretation of tests of ventilatory function. In: The ECSC in Technological and Social Research. Gijón, 1989; pp. 407-425.

10. Miller GJ, Saunders MJ, Gilson RJC, Ashcroft MT. Lung function of healthy boys and girls in Jamaica in relation to ethnic composition and habitual physical activity. Thorax 1977; 32: 486-496.

11. Pool JB, Greenough A. Ethnic variation in respiratory function in young children. Respir Med 1989; 83: 123-125.

12. Rahman MA, Ullah MB, Begum A. Lung function in teenage Bangladeshi boys and girls. Respir Med 1990; 84: 47-55.

13. Schoenberg JB, Beck GJ, Bouhuys A. Growth and decay of pulmonary function in healthy blacks and whites. Respir Physiol 1978; 33: 367-394.

14. Cotes JE. Lung function: assessment and application in medicine. 5th edition. Oxford, Blackwell Scientific Publications, 1993.

15. Yang T-S, Peat J, Keena V, Donnelly P, Unger W, Woolcock A. A review of the racial differences in the lung function of normal Caucasian, Chinese and Indian subjects. Eur Respir J 1991; 4: 872-880.

16. DeGroodt EG, Quanjer PhH, Wise ME, Van Zomeren BC. Changing relationships between stature and lung volumes during puberty. Respir Physiol 1986; 65: 139-153.

17. Borsboom GJJM, Van Pelt W, Quanjer PhH. Pubertal growth curves of ventilatory function: relationship with childhood respiratory symptoms. Am Rev Respir Dis 1993; 147: 372-378.

18. Rosenthal M, Cramer D, Bain SH, Denison D, Bush A, Warner JOP. Lung function in white children aged 4-19 years. II. Single breath analysis and plethysmography. Thorax 1993; 48: 803-808.

19. Hibbert ME, Lannigan A, Landau LI, Phelan PD. Lung function values from a longitudinal study of healthy children and adolescents. Pediatr Pulmonol 1989; 7: 101-109.

20. Hopper JL, Hibbert ME, Macaskill GT, Phelan PD, Landau LI. Longitudinal analysis of lung function growth in healthy children and adolescents. J Appl Physiol 1991; 70: 770-777.

21. Chiswick ML, Milner RDG. Crying vital capacity: measurement of neonatal lung function. Arch Dis Child 1976; 51: $22-27$. 
22. Gaultier $\mathrm{Cl}$. Lung volumes in neonates and infants. Eur Respir J 1989; 2 (Suppl. 4): 130s-134s.

23. Gaultier Cl, Boulé M, Allaire Y, Clément A, Girard F. Growth of lung volumes during the first three years of life. Bull Eur Physiopathol Respir 1979; 15: 1103-1116.

24. McCarthy MM, Spock A. Crying pulmonary function tests in children less than 2 years of age. Am Rev Respir Dis 1980; 121: 295-298.

25. Sutherland JM, Ratcliff JW. Crying vital capacity. Am J Dis Child 1961; 101: 67-74.

26. Berglund G, Karlberg P. Determination of the functional residual capacity in newborn infants. Acta Paediatr 1956; 45: 541-544.

27. Boon AW, Ward-McQuaid AD, Milner AD, Hopkin IE. Thoracic gas volume; helium functional residual capacity and air-trapping in the first six hours of life: the effect of oxygen administration. Early Hum Dev 1981; 5: 157-166.

28. Hanrahan JP, Tager IB, Castile RG, Segal MR, Weiss ST, Speizer FE. Pulmonary function measures in healthy infants. Am Rev Respir Dis 1990; 141: 1127-1135.

29. Moriette G, Chaussain M, Radvanyi Bouvet MF, Walti H, Pajot N, Relier JP. Functional residual capacity and sleep states in the premature newborn. Biol Neonate 1983; 43: 125-133.

30. Taussig LM, Harris TR, Lebowitz MD. Lung function in infants and young children. Am Rev Respir Dis 1977; 116: 233-239.

31. Tepper RS, Morgan WJ, Cota K, Wright A, Taussig LM, GHMA Pediatricians. Physiologic growth and development of the lung during the first year of life. Am Rev Respir Dis 1986; 134: 513-519.

32. Walti H, Moriette G, Radvanyi-Bouvet MF, et al. Influence of breathing pattern on functional residual capacity in sleeping newborn infants. J Devel Physiol 1986; 8: $167-172$.

33. Tepper RS, Reister T. Forced expiratory flows and lung volumes in normal infants. Pediatr Pulmonol 1993; 15: 357-361.

34. Auld PAM, Nelson NM, Cherry RB, Rudolph AJ, Smith CA. Measurement of thoracic gas volume in the newborn infant. J Clin Invest 1963; 42: 476-482.

35. Chu JS, Dawson P, Klaus M, Sweet AY. Lung volume and lung compliance measured concurrently in normal full-term and premature infants. Pediatrics 1964; 34: 525-532.

36. Doershuk CF, Downs TD, Matthews LW, Lough MD. A method for ventilatory measurements in subjects 1 month-5 years of age: normal results and observations in disease. Pediatr Res 1970; 4: 165-174.

37. Doershuk CF, Matthews LW. Airway resistance and lung volume in newborn infants. Pediatr Res 1969; 3 : 128-134.

38. Hatch DJ, Taylor BW. Thoracic gas volume in early childhood. Arch Dis Child 1976; 51: 859-864.

39. Kao LC, Keens TG. Decreased specific airway conductance in infant apnea. Pediatrics 1985; 76: 232-235.

40. Klaus M, Tooley WH, Weaver KH, Clements JA. Functional residual capacity in newborn infants measured by a rapid physical method. Am J Dis Child 1960; 100: 482484.

41. Phelan PD, Williams HE. Ventilatory studies in healthy infants. Pediatr Res 1969; 3: 425-432.

42. Radford M. Measurement of airway resistance and thoracic gas volume in infancy. Arch Dis Child 1974; 49: 611-615.

43. Stocks J, Godfrey S. Specific airway conductance in relation to postconceptional age during infancy. $J$ Appl Physiol: Respirat Environ Exercise Physiol 1977; 43: 144-154.

44. Beardsmore CS, MacFadyen UM, Moosavi SSH, Wimpress SP, Thompson J, Simpson H. Measurement of lung volumes during active and quiet sleep in infants. Pediatr Pulmonol 1989; 7: 71-77.

45. Geubelle F, Francotte M, Beyer M, Louis I, Logvinoff MM. Functional residual capacity and thoracic gas volume in normoxic and hyperoxic newborn infants. Acta Paediatr Belg 1977; 30: 221-225.

46. Krauss AN, Auld PAM. Pulmonary gas trapping in premature infants. Pediatr Res 1971; 5: 10-16.

47. Nelson NM, Prodhom LS, Cherry RB, Lipsitz PJ, Smith CA. Pulmonary function in the newbom infant. V. Trapped gas in the normal infant's lung. J Clin Invest 1963; 42: 1850-1856.

48. Gappa M, Fletcher ME, Dezateux CA, Stocks J. Comparison of nitrogen wash-out and plethysmographic measurements of lung volume in healthy infants. Am Rev Respir Dis 1993; 148: 1496-1501.

49. Sivan Y, Deakers TW, Newth CJL. An automated bedside method for measuring functional residual capacity by $\mathrm{N}_{2}$ wash-out in mechanically-ventilated children. Pediatr Res 1990; 28: 446-450.

50. Hanson JS, Shinozaki T. Hybrid computer studies of ventilatory distribution and lung volume. I. Normal newborn infants. Pediatrics 1970; 46: 900-914.

51. Gerhardt T, Reifenberg L, Hehre D, Feller R, Bancalari E. Functional residual capacity in normal neonates and children up to 5 years of age determined by a $\mathrm{N}_{2}$ washout method. Pediatr Res 1986; 20: 668-671.

52. Tepper RS, Asdell S. Comparison of helium dilution method and nitrogen wash-out messurements of functional residual capacity in infants and very young children. Pediatr Pulmonol 1992; 13: 250-254.

53. Greenough A, Stocks J, Nothen U, Helms P. Total respiratory compliance and functional residual capacity in young children. Pediatr Pulmonol 1986; 2: 321-326.

54. Greenough A, Hird MF, Everett L, Price JF. Importance of using lung function regression equations appropriate for ethnic origin. Pediatr Pulmonol 1991; 11: 207-211.

55. Buist AS, Adams BE, Sexton GJ, Azzam AM. Reference values for functional residual capacity and maximal expiratory flow in young children. Am Rev Respir Dis 1980; 122: 983-988.

56. Wall MA, Misley MC, Dickerson D. Partial expiratory flow-volume curves in young children. Am Rev Respir Dis 1984; 129: 557-562.

57. Bernstein IL, Fragge RG, Moshe G, Kreindler R, Ghory JE. Pulmonary function in children. J Allergy 1959; 30: 514-533.

58. Cook CD, Hamann JF. Relation of lung volumes to height in healthy persons between the ages of 5 and 38 years. J Pediatr 1961; 59: 710-714.

59. Engström I, Karlberg P, Kraepelin S. Respiratory studies in children. I. Lung volumes in healthy children, 6-14 years of age. Acta Paediatr 1956; 45: 277-294.

60. Geubelle F, Brény H. Volumes pulmonaires d'enfants sains, agés de 5 à 16 ans, d'origines ethniques différents. Poumon Coeur 1969; 25: 1065-1073.

61. Weng TR, Levison H. Standards of pulmonary function in children. Am Rev Respir Dis 1969; 99: 879-894.

62. Seely JE, Guzman CA, Becklake MR. Heart and lung function at rest and during exercise in adolescence. $J$ Appl Physiol 1974; 36: 34-40.

63. Thiemann H-H. Normwerte der Lungenfunktionsdiagnostik 
im Kindesalter. (Normal values for lung function in children). Z Erkrank Atm-Org 1976; 145: 249-257.

64. Von der Hardt H, Nowak-Beneke R. Lung volumes in healthy boys and girls, 6-15 years of age. Lung 1976; 154: 51-63.

65. Cotes JE, Dabbs JM, Hall AM, Heywood C, Laurence KM. Sitting height, fat-free mass and body fat as reference variables for lung function in healthy British children: comparison with stature. Ann Hum Biol 1979; 6: 307-314.

66. Solymar L, Aronsson P-H, Bake B, Bjure J. Nitrogen single-breath test, flow-volume curves and spirometry in healthy children, 7-18 years of age. Eur J Respir Dis 1980; 61: 275-286.

67. Haluszka J. Applicalion of the whole body plethysmography in examination of respiratory system in children. Predicted values, interrelation, methodological suggestions. National Institute for Mother and Child, ed. 1963; 18: 519-522.

68. Zapletal A, Paul T, Samanek M. Die Bedeutung heutiger Methoden der Lungenfunktionsdiagnostik zur Feststellung einer Obstruktion der Atemwege bei Kindern und Jugendlichen. (Significance of current methods of lung function assessment for establishing airways obstruction in children and adolescents). Z Erkrank Atm-Org 1977; 149: 343-371.

69. Michaelson ED, Watson H, Silva G, Zapata A, SerafiniMichaelson SM, Sackner MA. Pulmonary function in normal children. Bull Eur Physiopathol Respir 1978; 14: 525-550.

70. Binder RE, Mitchell CA, Schoenberg JB, Bouhuys A. Lung function among black and white children. Am Rev Respir Dis 1976; 114: 955-960.

71. DeMuth GR, Howatt WF. The growth of lung function. I. Lung volume. Pediatrics 1965; 35: 162-176.

72. Dirksen A, Groth S. Calculation of reference values for lung function tests. Bull Eur Physiopathol Respir 1986; 22: 231-237.

73. Pattishall EN, Helms RW, Strope GL. Noncomparability of cross-sectional and longitudinal estimates of lung growth in children. Am Rev Respir Dis 1987; 135: A22.

74. Sherrill D, Lebowitz M, Knudson R, Burrows B. Continuous longitudinal regression equations for pulmonary function measures. Eur Respir J 1992; 5: 452-462.

75. Merkus PJFM, Quanjer PhH. Cohort effects and paediatric pulmonary reference values. Eur Respir J 1990; 3: 299s.

76. Ghio AJ, Crapo RO, Elliott CG. Reference equations used to predict pulmonary function. Chest 1990; 97: 400-403.

77. Ghio AJ, Crapo RO, Elliott CG. Survey of reference equations used to predict pulmonary function in children. Pediatr Pulmonol 1990; 8: 126-127.

78. Pattishall EN. Pulmonary function testing reference values and interpretations in pediatric training programs. Pediatrics 1990; 85: 768-773.

79. Polgar G, Promadhat V. Pulmonary function testing in children: techniques and standards. W.B. Saunders Co., 1971;:

80. Taussig LM, Chernick V, Wood R, Farrell P, Mellins RB. Standardisation of lung function testing in children. Proceedings and recommendations of the GAP conference committee, Cystic Fibrosis Foundation. J Pediatr 1980; 97: 668-676.

81. Schrader PC, Quanjer PhH, van Zomeren BC, Wise ME. Changes in the $\mathrm{FEV}_{1}$-height relationship during pubertal growth. Bull Eur Physiopathol Respir 1984; 20: 381-388.
82. Engström I, Karlberg J, Karlberg P. Change in the vital capacity/height relationship during the age period between 12-21 years. Bull Eur Physiopathol Respir 1983; 19: 19-20.

83. Quanjer PhH, Helms P, Bjure J, Gaultier Cl. Standardization of lung function tests in paediatrics. Eur Respir J 1989; 2 (Suppl. 4): 121s-264s.

84. Cogswell JJ, Hull D, Milner AD, Norman AP, Taylor B. Lung function in childhood. 2. Thoracic gas volumes and helium functional residual capacity measurements in healthy children. Br J Dis Chest 1975; 69: 118-124.

85. Kraemer R, Zehnder M, Meister B. Intrapulmonary gas distribution in children. Respir Physiol 1986; 65: 127-137.

86. Nickerson BG, Young J, Kao LC. Correlation of lung volume measurements by body plethysmography and roentgenograph in young infants. Am Rev Respir Dis 1987; 135: A471.

87. Chapman B, O'Callaghan C, Coxon R, et al. Estimation of lung volume in infants by echo planar imaging and total body plethysmography. Arch Dis Child 1990; 65: 168-170.

88. Naimark A, Cherniack RM. Compliance of the respiratory system and its components in health and obesity. $J$ Appl Physiol 1960; 15: 377-382.

89. Sharp JT, Henry JP, Sweany SK, Meadows WR, Pietras RJ. Effects of mass loading the respiratory system in man. J Appl Physiol 1964; 19: 959-966.

90. Barrera F, Reidenberg MM, Winters WL. Pulmonary function in the obese patient. Am J Med Sci 1967; ??: 785-796.

91. Gilbert R, Sipple JH, Auchincloss JH. Respiratory work and control of breathing in obese subjects. J Appl Physiol 1961; 16: 21-26.

92. Bedell GN, Wilson WR, Seebohm DM. Pulmonary function in obese persons. J Clin Invest 1958; 37: 10491060.

93. Emirgil C, Sobol BJ. The effects of weight reduction on pulmonary function and the sensitivity of the respiratory center in obesity. Am Rev Respir Dis 1973; 108: 831-842.

94. Ray CS, Sue DY, Bray G, Hansen JE, Wasserman K. Effects of obesity on respiratory function. Am Rev Respir Dis 1983; 128: 501-506.

95. Glindmeyer HW, Diem JE, Jones RN, Weill H. Noncomparability of longitudinally and cross-sectionally determined annual change in spirometry. Am Rev Respir Dis 1982; 125: 544-548.

96. Dontas AS, Jacobs DR, Corcondilas A, Keys A, Hannan P. Longitudinal versus cross-sectional vital capacity changes and affecting factors. J Gerontol 1984; ??: 430-438.

97. Louis TA, Robins J, Dockery DW, Spiro A III, Ware $\mathrm{JH}$. Explaining discrepancies between longitudinal and cross-sectional models. J Chron Dis 1986; 39: 831-839.

98. Ware JH, Dopckery DW, Louis TA, Xu X, Ferris BG, Speizer FE. Longitudinal and cross-sectional estimates of pulmonary function decline in never-smoking adults. Am J Epidemiol 1990; 132: 685-700.

99. Van Pelt W, Borsboom GJJM, Rijcken B, Schouten JP, Van Zomeren BC, Quanjer PhH. Discrepancies between longitudinal and cross-sectional change in ventilatory function in 12 years of follow-up. Am Rev Respir Dis 1994; 149: 1218-1226.

100. Roberts CM, MacRae KD, Winning AJ, Adams L, Seed WA. Reference values and predictions equations for normal lung function in a nonsmoking white urban population. Thorax 1991; 46: 643-650. 
101. Roca J, Sanchis J, Agusti-Vidal A, et al. Spirometric reference values from a Mediterranean population. Bull Eur Physiopathol Respir 1986; 22: 217-224.

102. Smolej-Narancic N, Pavlovic M, Rudan P. Ventilatory parameters in healthy nonsmoking adults of Adriatic island (Yugoslavia). Eur Respir J 1991; 4: 955-964.

103. Stevens WH, van Hartevelt JH, The PEK, Smink HAJ, Quanjer $\mathrm{PhH}$. Validity of ECSC prediction equations for spirometric and flow-volume indices in 18 year old Dutch conscripts. Eur Respir J 1994; 7: 29-34.

104. Van Pelt W, Quanjer PhH, Borsboom G, et al. Comparability of reference populations from Holland and Italy (Abstract). Eur Respir J 1990; 3: 485.

105. DuBois AB, Botelho SY, Bedell GN, Marshall R, Comroe $\mathrm{JH}$ Jr. A rapid plethysmogrnphic method for measuring thoracic gas volume; a comparison with a nitrogen washout method for measuring functional residual capacity. J Clin Invest 1956; 35: 322-326.

106. Tierney DF, Nadel JA. Concurrent measurements of functional residual capacity by three methods. J Appl Physiol 1962; 17: 871-873.

107. Woitowitz HJ, Buchheim FW, Woitowitz R. Zur Theorie und Praxis der Ganzkörperplethysmographie in der Lungenfunktionsanalyse. (Theory and practice of whole body plethysmography in assessment of lung function). Prax Pneumol 1967; 8: 449-471.

108. Lapp NL, Amandus HE, Hall R, Morgan WKC. Lung volumes and flow rates in black and white subjects. Thorax 1974; 29: 185-188.

109. Lanese RR, Keller MD, Foley MF, Underwood EH. Differences in pulmonary function tests among whites, blacks, and American Indians in a textile company. $J$ Occup Med 1978; 20: 39-44.

110. O'Brien RJ, Drizd TA. Roentgenographic determination of total lung capacity: normal values from a national survey. Am Rev Respir Dis 1983; 128: 949-952.

111. Dockery DW, Speizer FE, Ware JH, Ferris BG Jr. Growth of pulmonary function between 6-18 years of age. Am Rev Respir Dis 1987; 135: A22.

112. Schrader PC, Quanjer P, Borsboom G, Wise ME. Evaluating lung function and anthropometric growth data in a longitudinal study on adolescents. Hum Biol 1984; 56: 365-381.

113. Strope GL, Helms RW. A longitudinal study of spirometry in young black and white children. Am Rev Respir Dis 1984; 130: 1100-1107.

114. Crapo RO, Gardner RM, Berlin SL, Morris AH. Automation of pulmonary function equipment. Chest 1986; 90: 1-2.

115. Hutchinson J. On capacity of lungs and on respiratory function with view to establishing a precise and easy method. Med Chir Trans (Lond) 1846; 29: 137.

116. Drouet D, Kauffmann F, Brille D, Lellouch J. Valeurs spirographiques de référence. Modèles mathématiques et utilisation pratique. Bull Eur Physiopathol Respir 1980; 16: 747-767.

117. Chinn S, Rona RJ. Height and age adjustment for crosssectional studies of lung function in children aged 6-11 years. Thorax 1992; 47: 707-714.

118. Quanjer PhH, Borsboom GJJM, Brunekreef B, et al. Spirometric reference values for white European children and adolescents: Polgar revisited. Pediat Pulmonol (in the press).

119. Polgar G, Weng TR. The functional development of the respiratory system from the period of gestation to adulthood. Am Rev Respir Dis 1979; 120: 625-695.

120. Respiratory mechanics in infants: physiologic evaluation in health and disease. Official statement of American
Thoracic Society and European Respiratory Society. Eur Respir J 1993; 6: 279-310.

121. Stocks J. Standardisation of lung function testing in infants. Progress in Respiration Research, Paediatric Respiratory Disease. Basel, Karger, 1981; 17: pp. 9-21.

122. Tanner JM. Fallacy of per weight and per surface area standards and their relation to spurious correlation. $J$ Appl Physiol 1949; 2: 1-15.

123. Quanjer PhH. Predicted values: how should we use them? Thorax 1988; 43: 663-664.

124. Schmalisch G, Wauer RR. Percentiles for quantification of interindividual parameter distributions in lung function tests. Research in Perinatal Medicine. In: Grauel EL, SyllmRapoport I, Wauer RR, eds. Leipzig, VEB Georg Thieme 1986; pp. 116-129.

125. American Thoracic Society Statement. Evaluation of impairment/disability secondary to respiratory disease. Am Rev Respir Dis 1982; 126: 945-951.

126. Miller MR, Pincock AC. Predicted values: how should we use them? Thorax 1988; 43: 265-267.

127. Kraemer R, Frey U, Sommer CW, Russi E. Short-term effect of albuterol, delivered via a new auxiliary device, in wheezy infants. Am Rev Respir Dis 1991; 144: 347-351.

128. Dezateux CA, Fletcher ME, Rabbette PS, Stanger LJ, Stocks J. A Manual of Infant Lung Function Testing. In: Portex Anaesthesia, Intensive Therapy and Respiratory Medicine Unit, Institute of Child Health, London, 1991; ISBN 0-9518956-0-5.

129. Hermanussen M, Burmeister J. Children do not grow continuously but in spurts. Am J Hum Biol 1993; 5: 615-622.

130. Lampl M, Veldhuis JD, Johnson ML. Saltation and stasis: a model of human growth. Science 1992; 258: 801-803.

131. Cox LA. A guide to the measurement and assessment of growth in children. UK, Castlemead Publ, ISBN 094855-130, 1992.

132. Tanner JM, Hayashi T, Preece M, Cameron N. Increase in length of leg relative to trunk in Japanese children and adults from 1957 to 1977: a comparison with British and with Japanese Americans. Ann Hum Biol 1982; 9: 411-423.

133. Hibbert ME, Lanigan A, Raven J, Phelan PD. Relation of arm span to height and the prediction of lung function. Thorax 1988; 43: 657-659.

134. Van Ganse W, Billiet L, Ferris BG Jr. Medical criteria for the selection of normal subjects. Normal values for respiratory function in man. Arcangeli $\mathrm{P}$, Cotes JE, eds. Italy, Panminerva Medica, 1969; pp. 15-27.

135. Strope GL, Stewart PW, Henderson FW, Ivins SS, Stedman HC, Henry MW. Lung function in school-age children who had mild lower respiratory illness in early childhood. Am Rev Respir Dis 1991; 144: 655-662.

136. Cogswell JJ, Hull D, Milner AD, Norman AP, Taylor B. Lung function in childhood. I. The forced expiratory volumes in healthy children using a spirometer and reverse plethysmograph. Br J Dis Chest 1975; 69: 40-50.

137. Godfrey S, Kamburoff PL, Nairn JL. Spirometry, lung volumes and airway resistance in normal children ages 5 to 18 years. Br J Dis Chest 1970; 64: 15-24.

138. Weiner JS, Lourie JA. Human biology: a guide to field methods. Oxford, Blackwell Scientific Publ.

139. Sobol BJ, Sobol PG. Percent predicted as the limit of normal in pulmonary function testing: a statistically valid approach. Thorax 1979; 34: 1-3.

140. Johnson DC. Predicted values: how should we use them? Thorax 1989; 44: 527. 